\title{
CONCENTRAÇÃO FUNDIÁRIA E DINÂMICA IMOBILIÁRIA EM UMA CIDADE QUE JÁ SURGIU COMO NEGÓCIO: UM ESTUDO A PARTIR DE PRIMAVERA DO LESTE, MATO GROSSO
}

Resumo: Este artigo evidencia as contradições da produção do espaço urbano da cidade de Primavera do Leste, Mato Grosso, com ênfase aos negócios fundiários e às implicações espaciais de uma cidade que já surgiu como um grande negócio. Considera uma perspectiva que propõe uma abordagem caracterizada pela primazia do urbano, relativizando o papel da agricultura capitalista nos processos de urbanização desta e de outras cidades implantadas principalmente a partir da década de 1970 no contexto da expansão territorial da acumulação capitalista rumo ao Centro-Oeste do Brasil. Tendo como base levantamento bibliográfico e realização de trabalhos de campo, aprofunda os conteúdos de uma urbanização até hoje controlada por um pequeno grupo de detentores do poder econômico e político.

Palavras-Chave: Urbano. Agronegócio. Produção do Espaço. Concentração fundiária. Mato Grosso.

\section{LAND CONCENTRATION AND REAL ESTATE DYNAMIC IN A CITY THAT HAS ALREADY EMERGED AS A BUSINESS: A STUDY FROM PRIMAVERA DO LESTE, MATO GROSSO}

Abstract: This research highlight the contradictions in the production of urban space in the city of Primavera do Leste, Mato Grosso, emphasizing land businesses and the spatial implications of a city that has emerged as a major business. It considers a critical perspective of the production of space and puts into perspective the role of capitalist agriculture in the urbanization processes of this and other cities established mainly after the 1970s in the context of the territorial expansion of capitalist accumulation towards the Midwest of Brazil. Based on a bibliographic review, interviews and field work, we analyzed the components of an urbanization still controlled today by a small group of those who have economic and political power.

Keywords: Urban. Agribusiness. Production of Space. Land Concentration. Mato Grosso.

\section{CONCENTRACIÓN DE TIERRA Y DINÁMICA INMOBILIÁRIA EN UNA CIUDAD QUE YA SURGIÓ COMO NEGOCIO: UN ESTUDIO A PARTIR DE PRIMAVERA DO LESTE, MATO GROSSO}

\footnotetext{
1 Instituto Federal de Mato Grosso (IFMT), Campus Primavera do Leste, Brasil, liviageousp@gmail.com, https://orcid.org/0000-0001-5247-1582
} 
Resumen: Este artículo evidencia las contradicciones de la producción del espacio urbano de la ciudad Primavera do Leste, en Mato Grosso-Brasil, con especial atención a los negocios de la tierra y a las consecuencias espaciales de una ciudad que surgió como un gran negocio. Considera una perspectiva crítica a la producción del espacio, que propone un abordaje marcado por la primacía de lo urbano, y relativiza el papel de la agricultura capitalista en los procesos de urbanización de esta y otras ciudades asentadas, principalmente a partir de la década de 1970, en un contexto de expansión territorial de la acumulación capitalista hacia el centro-oeste de Brasil. Basada en estudios bibliográficos, entrevistas y trabajos de campo, se profundiza, así, los hechos de una urbanización controlada, hasta hoy, por un pequeño grupo de detentores del poder económico y político.

Palabras clave: Urbano. Agronegocio. Producción del Espacio. Concentración de tierra. Mato Grosso.

\section{Introdução}

Grande parte das pesquisas sobre essas cidades cuja urbanização é atrelada mais fortemente ao "agronegócio"2, tal como Primavera do Leste, são, com frequência, realizados a partir do agrário. Tal abordagem caracteriza essas cidades, em grande medida, como um suporte aos serviços e às infraestruturas demandados pelo campo ou pela agricultura. Trazemos um estudo que pretende (re) colocar o domínio do urbano nos processos da produção do espaço, desvelando a produção de cidades como um grande e rentável negócio.

A partir do urbano e de uma perspectiva crítica da produção do espaço, elucidam-se os fundamentos das contradições espaciais de Primavera do Leste, localizada a 240 quilômetros de Cuiabá (mapa 1) e uma das cidades brasileiras cuja dinâmica econômica está de modo significativo relacionada, ao menos em comparação com outras cidades mato-grossenses e brasileiras, à agricultura capitalista mecanizada.

A dinâmica da acumulação capitalista nessas cidades conhecidas pelo denominado "agronegócio" não pode ser pensada em função unicamente dos capitais mais diretamente ligados à agricultura mecanizada. É preciso também problematizar conteúdos da vida cotidiana, em um processo no qual o homem ao produzir o espaço produz a própria vida. Nesta perspectiva, consideramos que

\footnotetext{
2 Entendemos "agronegócio" como o que Oliveira (2007) denomina de "agricultura capitalista", ou seja, aquela agricultura que produz mercadorias para serem vendidas, principalmente no mercado mundial, e que tem como objetivo primordial a acumulação.
} 
Primavera do Leste já surge urbana desde o início de sua elaboração e planejamento no final da década de 1970, bem como colocamos a centralidade da investigação no urbano e na propriedade privada da terra.

\section{Mapa 1. Localização de Primavera do Leste no estado de Mato Grosso e no centro oeste brasileiro}
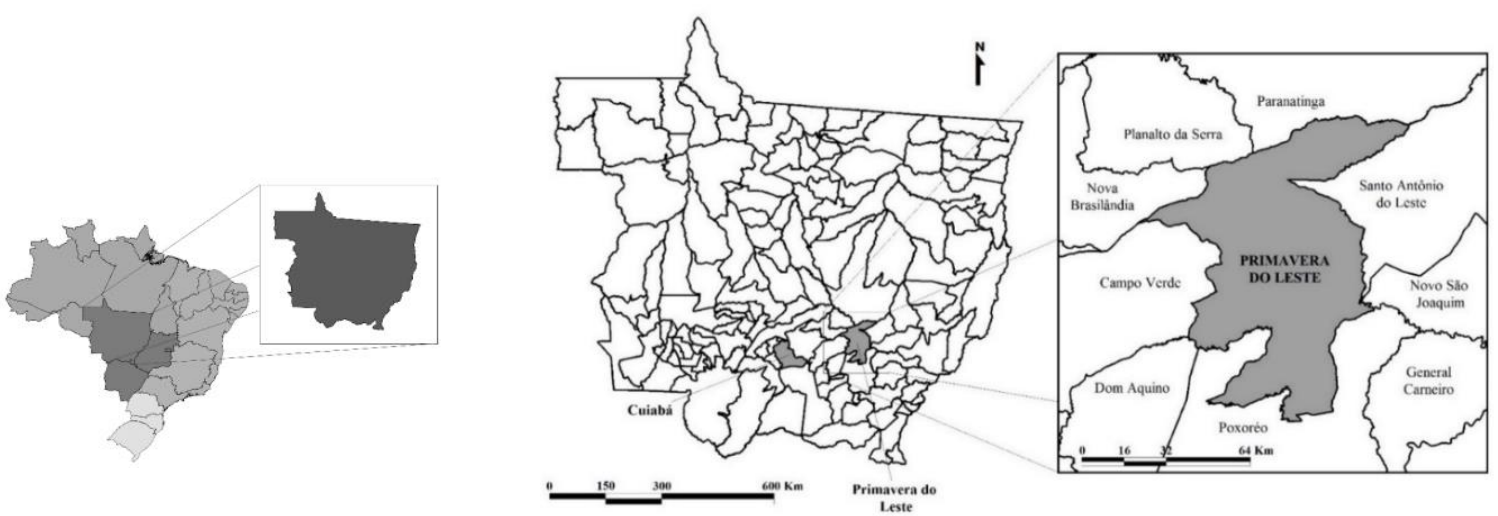

Mapa elaborado por Alcântara, W.M.; Fioravanti, L.M.

Inverter a análise geralmente empregada a respeito dessas cidades permite problematizar a urbanização como condição da acumulação, descortinando, de um lado, uma produção da fronteira do capital rumo ao sudeste mato-grossense subsumida aos agentes hegemônicos da produção do espaço e, de outro, a prática socioespacial e a vida cotidiana que se produz neste processo inerentemente expropriatório. Desvelam-se alguns dos conflitos que foram produzidos em uma cidade cujos processos de valorização e de reprodução do capital realizaram-se de modo intenso, agudizado em relação àqueles de realização da vida.

O que aparece num primeiro momento no plano da paisagem, com intermináveis campos monocultores ou inúmeras lojas e serviços relacionados a insumos e maquinários agrícolas - em um cenário reforçado pela própria análise do mapa 2 e da foto 1, com a mancha edificada da cidade cercada por plantações poderia corroborar para uma importância sobre-estimada das atividades agrárias ou voltada estritamente ao "agronegócio" nos processos espaciais de Primavera do Leste e de tantas outras cidades. 


\section{Mapa 2. Município e núcleo urbano de acordo com delimitação do IBGE}

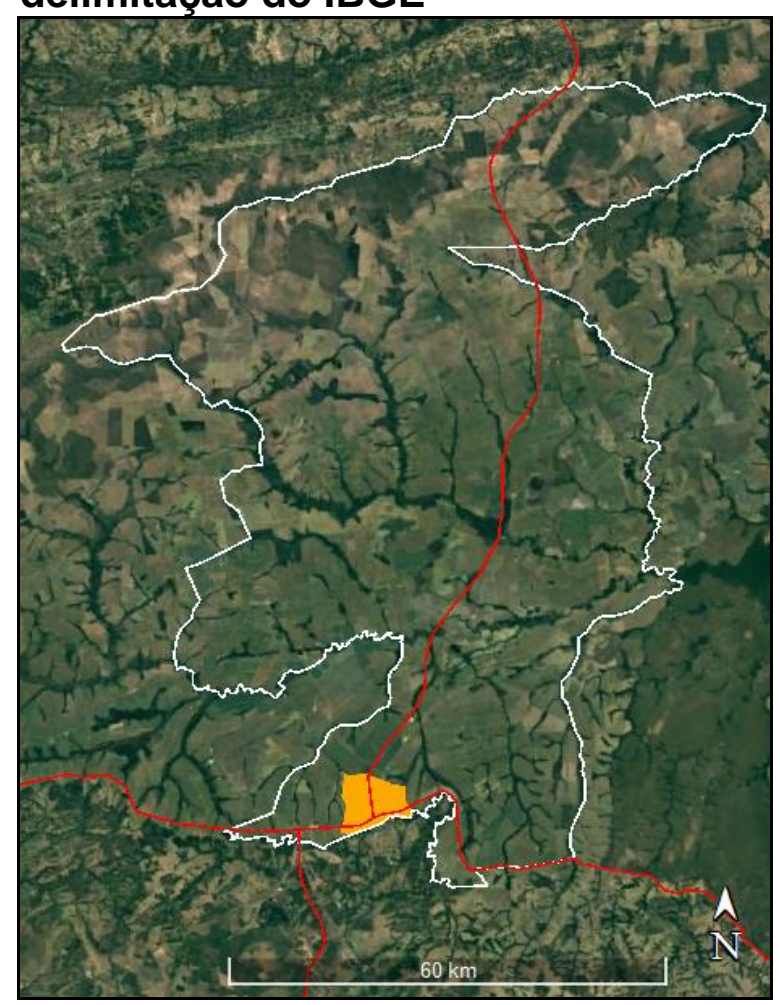

Em branco, delimitação do município. Em laranja, núcleo urbano segundo critérios administrativos do IBGE. Estradas em vermelho: de leste a oeste, BR-70; de norte a sul, MT-130. Imagem extraída e elaborada pela autora no software Google Earth Pro.

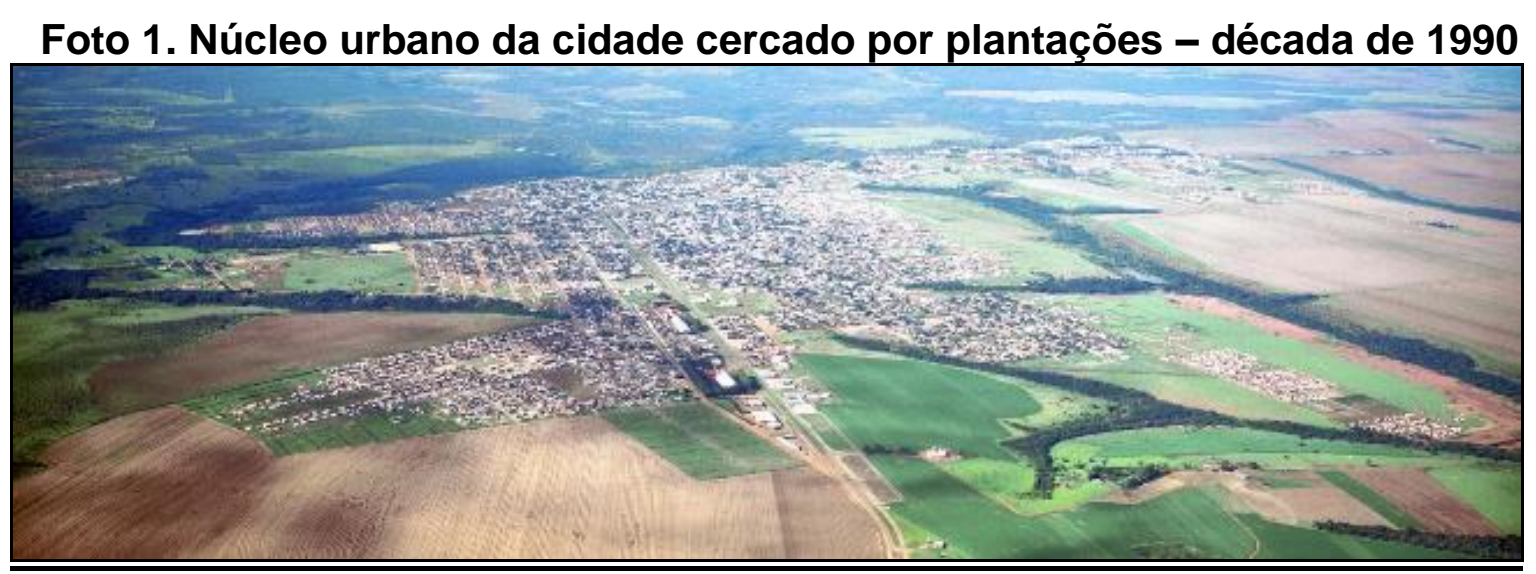

Núcleo urbano de Primavera do Leste cercado por plantações e áreas para plantio. Fonte: Câmara Municipal de Primavera do Leste, 2016.

Tanto no decorrer da produção da fronteira quanto atualmente diante de um contexto de uma agricultura cada vez mais mecanizada e mundializada, os núcleos urbanos fornecem um suporte logístico às atividades ligadas à exploração agrária. $\mathrm{Na}$ cidade, estão concentradas atividades voltadas a atender as demandas do campo, tais como: serviços financeiros e jurídicos, assistência técnica, fornecimento 
de insumos e de máquinas agrícolas, armazéns e indústrias que beneficiam a produção do campo, estabelecimentos comerciais e bancários. A cidade, no entanto, longe de ser um local passivo onde se concentram as atividades vinculadas ao campo - tanto atreladas à produção de commodities propriamente dita quanto aquelas vinculadas a infraestruturas e aos serviços especializados - foi a condição para que um campo cada vez tecnificado e financeirizado pudesse se realizar.

É nesse sentido que Volochko (2013, p. 24) afirma que "onde a terra está sendo cultivada como meio de produção das commodities internacionais (...) a extensão das grandes propriedades monocultoras não pode prescindir da centralização urbana". Essa centralização urbana abrange, segundo o autor (2013), uma centralização técnica (por meio de atividades de controle e gestão da produção e de serviços de consultoria); política (por meio de políticas direcionadas ao "agronegócio"); e econômica (já que é na cidade onde estão as infraestruturas, os serviços, a concentração da mão de obra, assim como a elaboração de pesquisas e produção de parcela dos insumos agrícolas).

Todavia, mesmo que seja onde esteja concentrada a maior parte da infraestrutura, serviços e mão de obra, a cidade não pode, na perspectiva aqui adotada, ser vista como um lócus subordinado ao campo. Tal abordagem tenderia a considerar o avanço da acumulação territorial do capital do Centro-Sul do Brasil para as regiões Centro-Oeste e Norte somente como uma expansão da "fronteira agrícola", caracterizando essas cidades, sobretudo, como um suporte aos serviços e às infraestruturas demandados pelo "agronegócio". Assim, relativizamos, a importância da agricultura capitalista no processo de ocupação e produção dessas cidades, admitindo que os negócios com a propriedade privada da terra e da urbanização transformar-se-iam em tão relevantes quanto aqueles voltados à produção agrícola.

Tal como muitas outras cidades mato-grossenses ao longo do eixo da BR-163 (como Nova Mutum, Lucas do Rio Verde, Sorriso e Sinop) e de grande parcela da extensão territorial do Brasil, alcançando também o semiárido (associado à fruticultura), os cerrados nordestinos (sul do Maranhão, do Piauí e oeste da Bahia) e o norte de Tocantins, Primavera do Leste surgiu como um rentável empreendimento e guarda, desde sua implantação, conteúdos primordialmente urbanos.

Como afirma Simoni Santos (2015), a urbanização era justamente a condição para a acumulação brasileira se realizar. A fronteira do capital ancorada nas 
atividades propriamente urbanas e implantação de cidades, neste contexto, não apenas precedeu a expansão da sojicultura, como se constitui em um grande negócio. O ritmo das relações espaciais em Primavera do Leste foi urbano, seguindo uma racionalidade instrumental e uma lógica capitalista que se impôs com força e violência na produção da fronteira da acumulação rumo ao sudeste mato-grossense.

O domínio do espaço, que foi sendo delineado conforme a expansão territorial do capital se realizava, favoreceu grandes empresas, poderosos empresários e latifundiários e antigas oligarquias econômicas e políticas - compondo grupos que se tornariam hegemônicos nessas cidades, em um processo com profundas implicações na estrutura fundiária e na dinâmica imobiliária.

Primavera do Leste nasce, como projeto de cidade, com a incorporação da Amazônia ao processo de expansão territorial da acumulação capitalista brasileira, dando vazão aos capitais excedentes urbano-industriais centralizados no Centro-Sul do país. Neste momento de rápida inserção do território amazônico às estratégias do capital, Mato Grosso passa a ser considerado como "portal" da Amazônia e visto como uma etapa territorial de ocupação e integração econômica para o CentroOeste e Norte brasileiro (MORENO, 2007). Tal expansão territorial realizou-se no seio da produção da fronteira do capital pela privatização das terras, esquadrinhadas sob o comando de latifundiários por meio da transformação de terras devolutas, sob a jurisdição do Estado, em propriedades privadas capitalistas nas mãos de grandes empresários e empresas.

Neste contexto, o modo pelo qual a propriedade foi dominada e fracionada por esses grandes empresários do Centro-Sul brasileiro teve como consequência um acirramento da concentração de terra, de capital e de poder. $O$ forte nó entre esses três elementos, pormenorizado nas obras do sociólogo brasileiro José de Souza Martins (1994; 2010) e uma das características fundantes da sociedade brasileira, ajuda-nos a explicar as contradições espaciais tanto de Primavera do Leste quanto de demais cidades mato-grossenses.

Resultado de uma pesquisa alicerçada em levantamento bibliográfico, realização de trabalhos de campo e de entrevistas, este artigo se divide em quatro seções, além desta introdução e das considerações finais. Na primeira, são tecidas reflexões sobre o conceito de fronteira e alguns dos conteúdos da "invenção de cidades" face à expansão territorial capitalista rumo ao Centro-Oeste. Já na segunda, evidencia-se que o que desponta como uma "fronteira agrícola" também é uma 
fronteira eminentemente urbana, cujos negócios fundiários são esmiuçados na terceira seção. Por fim, na última parte, expomos um breve debate sobre uma homogeneidade social e estética resultante da ingerência dos "pioneiros" da cidade tanto sobre a propriedade privada capitalista da terra quanto nas diversas nuances da vida cotidiana. Apontam-se práticas higienistas que relegam os pobres não somente às periferias, mas que tendem, inclusive, a expulsá-los da própria cidade. Revelam-se, neste sendo, outras facetas de uma cidade que, no senso comum, aparece como um local em que todos podem enriquecer e ter a tão almejada "qualidade de vida".

\section{Considerações iniciais sobre a fronteira}

Para compreender a produção do espaço primaverense, é preciso desvendar as estratégias políticas e econômicas que permearam a produção do espaço desde sua implantação, quando projetos e ações de grande envergadura passam a incorporar a Amazônia Legal brasileira ${ }^{3}$ às dinâmicas da acumulação capitalista. Da mesma forma que outras cidades que surgiram a partir da década de 1970 no contexto de expansão territorial do capitalismo brasileiro rumo às regiões Norte e Centro-Oeste, Primavera do Leste nasceu em um contexto no qual as terras foram dominadas privadamente por grandes empresários.

Como afirma Becker (1982), a fronteira amazônica oferecia grandes atrativos à reprodução do capital, constituindo-se como uma "frente avançada da sociedade industrial e urbana que nela buscam novos recursos para sua expansão" (BECKER, 1982, p. 9). Neste contexto, vale lembrar que, para José de Souza Martins (2014, p. 157), a "teoria da fronteira é (...) basicamente, um desdobramento da teoria da expansão territorial do capital", em um movimento no qual "novos terrenos são ocupados de modo capitalista quando é possível extrair deles a renda capitalista da terra". É justamente devido à essa expansão própria ao capitalismo que Sérgio Martins (1993, p.23) afirma que a fronteira faz referência a um "espaço submetido a uma contínua redefinição", no qual se sobrepõem relações aparentemente fragmentadas que seriam alteradas pela ação do Estado em função dos interesses em jogo - neste caso, a continuidade da acumulação capitalista.

\footnotetext{
${ }^{3}$ A Amazônia Legal brasileira é formada pelos estados do Acre, Amapá, Amazonas, Mato Grosso, Pará, Rondônia, Roraima e Tocantins, além de parcela do Maranhão, constituindo-se uma região cuja delimitação foi criada pelo governo federal com o objetivo de facilitar a implantação de programas e projetos que a inserissem de forma mais intensa aos processos de acumulação capitalista.
} 
Para Martins (1996, p.52), a fronteira abrange um momento (frente pioneira) marcado por "uma nova racionalidade econômica, pela constituição formal e institucional de novas mediações políticas, pela criação do novo vinculado à expansão dos mercados, induzindo à modernização e novas concepções de vida". A chegada desta modernização ocorre com conflitos em relação aos usos que já existiam em determinado espaço. Da mesma forma, as novas concepções de vida são distintas daquelas que predominavam até então (como a dos indígenas e a dos posseiros) e tendem a ser marcadas pelo tempo e pela racionalidade do capital.

A noção de fronteira, central para elucidarmos a produção do espaço nas cidades mato-grossenses, envolve, portanto, significativas transformações espaciais (aí, evidentemente, incluindo-se, as sociais) alavancadas pelo avanço territorial capitalista, colocando o foco da investigação na integração territorial de novos espaços ao movimento de produção e reprodução capitalista, bem como reiterando sua dimensão espacial e temporal. Nesta perspectiva, a fronteira é não só resultado da articulação entre estratégias políticas e econômicas, mas também conflito e movimento, sendo mobilizada e (re)criada diante da expansão geográfica do capital bem como da sobrevivência de populações mais pobres e expropriadas que passam a não ser mais bem-vindas ou encontrar meios de sobrevivência em determinado lugar e deslocam-se para novos espaços. Guarda, portanto, uma relação de integração-desintegração: ao mesmo em que se refere a um movimento no qual determinado espaço é integrado mais intensamente às estratégias de acumulação capitalista, a lógica de quem se apropriava desses espaços é desintegrada e tendencialmente subsumida face à reprodução do capital e à dominação do espaço empreendida pelos agentes hegemônicos.

A pressão do capital sobre terras supostamente disponíveis na fronteira resultou na expulsão de posseiros e indígenas, de modo que ambas têm como conteúdo serem produzidas como o "lugar do conflito" - como coloca Martins (2014) a respeito da noção de fronteira - no qual diferentes segmentos sociais entram em contato por meio um processo marcado por diferenças e também pela violência e intolerância (MARTINS, 2014).

No caso da fronteira amazônica e particularmente da fronteira matogrossense, a expansão territorial da acumulação se impôs de modo notadamente hegemônico, empreendido pelo grande capital e havendo uma intensa superposição acelerada de lógicas espaciais pretéritas. Neste momento do deslocamento da 
produção da fronteira rumo à Amazônia, surgem como conteúdos específicos a intensidade dos processos que incorporam Mato Grosso à dinâmica da acumulação, bem como a velocidade acentuada de realização das estratégias capitalistas dada pela força dos agentes sociais envolvidos neste momento (primordialmente, grandes capitalistas nacionais, estrangeiros e Estado).

Como afirma Guimarães Neto (2002, p. 151), a velocidade pela qual ocorria a ocupação da Amazônia era primordial não somente para compor um discurso de progresso, mas para controlar a vida da população mais pobre que não tinha acesso à "rapidez das realizações materiais e técnicas" desses espaços. A velocidade da ocupação e o discurso de que era preciso trabalhar (e rápido) contribuía, assim, para o domínio do espaço por parte dos grandes empresários nessas cidades que surgiam.

(...) pode-se dizer que os donos dos meios econômicos à exploração da riqueza da Amazônia foram os que efetivamente detiveram o poder de apropriação e 'conquista' da terra. O empresariado teve a supremacia da velocidade na Amazônia, e, portanto, tudo o que utilizou para se locomover, construir e dirigir envolveu o controle do tempo (...) (GUIMARÃES NETO, 2002, p. 156).

Neste sentido, como um importante conteúdo da produção da fronteira matogrossense há a expansão da acumulação capitalista e novos processos implantados com grande velocidade e rentabilidade, em uma modernização que se implanta praticamente sobre o que era visto como espaço vazio (SIMONI SANTOS, 2015). O considerado despovoamento da região e a vastidão de terras estrategicamente vistas como sem dono facilitavam, de acordo com Becker (1982), a articulação do território amazônico à dinâmica capitalista centralizada no Centro-Sul do Brasil.

A intensidade dos processos de urbanização, que impuseram a lógica capitalista praticamente sem um estágio de amortecimento anterior (SIMONI SANTOS, 2015) e outras etapas de desenvolvimento das forças produtivas que tornassem mais gradual a realização dos capitais urbano e industriais, foram recrudescidas diante da concomitante dominação privada e monopolização das terras. Essa particularidade trouxe novos conteúdos da urbanização não somente em Primavera do Leste, mas em outras cidades também concebidas e implantadas neste momento de constituição da fronteira e atreladas a projetos de colonização privados. 
Neste sentido, Oliveira (1997) e Becker (1994) salientam que a ocupação da fronteira amazônica deve ser entendida diante da propriedade privada capitalista da terra e da lógica dos monopólios. Essa particularidade a diferenciaria da constituição de outros espaços de fronteira.

Na Amazônia, na atualidade, o processo tem a característica da fase monopolista do capitalismo. Estamos agora, diante da lógica ditada por uma ação de monopólios privados ou públicos, não há mais disputa no e pelo mercado. Há tão somente a imposição dos monopólios. A mercadoria que comanda o processo de ocupação é a propriedade privada da terra. Assim, a produção da cidade, de certa forma precede o campo, ainda que propagandisticamente, o campo possa estar sendo vendido primeiro. São as cidades que se impõem na Amazônia matogrossense. É a lógica dos monopólios privados que se instauram e determinam a lógica do campo (OLIVEIRA, 1997, p. 145-146. Grifos nossos).

Para Oliveira (1997), compreender a ocupação do grande norte de Mato Grosso - e, em nossa perspectiva, também do sudeste do estado - envolve considerar necessariamente o papel dos projetos agropecuários financiados pelos incentivos fiscais da SUDAM $^{4}$ e as políticas territoriais que possibilitaram que grandes capitalistas nacionais e estrangeiros também se transformassem em latifundiários.

Da mesma forma, é justamente na urbanização que se encontra a razão para essa voracidade dos processos de conformação da fronteira, em um processo no qual o incentivo à ocupação da região via incentivos fiscais ocorreu de modo praticamente simultâneo à implantação de plantas industriais e infraestruturas de transporte e de comunicação - possibilitando, por meio da produção do espaço, novos espaços para a acumulação do capital (SIMONI SANTOS, 2015).

Diversos autores se debruçaram sobre o expropriatório processo de ocupação e dominação da Amazônia brasileira - como Martins (2010, 2014), Moreno (2007) e Oliveira $(1997 ; 2016)$ - destacando que, diante de uma nova escala de incorporação desse território às estratégias capitalistas, há um impetuoso processo de monopolização fundiária cuja lógica capitalista repercutiu diretamente na

\footnotetext{
${ }^{4}$ A SUDAM (Superintendência de Desenvolvimento da Amazônia, implantada em 1966) é instrumento de política econômica e territorial governo federal, implantado em 1966 com o objetivo de desenvolver programas setoriais com o objetivo de, por meio de medidas como cessão de incentivos fiscais e implantação de obras de infraestrutura, inserir a Amazônia de modo mais intenso aos processos de reprodução do capital.
} 
expropriação dos antigos habitantes do espaço amazônico e cedeu lugar a empresários e latifundiários. Acirra-se dramaticamente neste momento a luta pelo espaço entre seus agentes, expressa por meio da intensificação da violência com a chegada dos empresários urbanos, que, somados às antigas e ainda atuantes oligarquias econômicas e políticas, expandiram seu raio de atuação rumo às terras de indígenas, de posseiros e de antigos colonos.

\section{De uma fronteira agrícola a uma fronteira urbana}

A concepção e implantação de Primavera do Leste são resultado de um projeto previamente elaborado e calculado iniciou-se no final dos anos 1970 com a expansão da acumulação territorial do capital, que ocorria por meio da concentração fundiária e dos mais diversos arcaísmos. Dentre eles, o caráter rentista da propriedade privada da terra e a necessidade de mecanismos vinculados propriamente à produção de capital, como detalha Martins (1994), baseados em práticas como a escravidão por dívida e a grilagem de terras.

As terras que eram dominadas na expansão da fronteira eram, sobretudo, terras para "reserva patrimonial" e "reserva de valor" (OLIVEIRA, 1997; 2007), utilizadas por capitalistas principalmente para especulação e obtenção de incentivos fiscais (abundantes nos programas de incentivos à ocupação da Amazônia).

A partir da década de 1970 e por meio diversas políticas territoriais de ocupação, o regime militar brasileiro passa a patrocinar de forma mais intensa o acesso à terra na Amazônia aos grandes grupos econômicos, nacionais e internacionais (OLIVEIRA, 1997). Segundo o autor (1997), esses grupos tinham como objetivo primordial ao investirem na fronteira a isenção fiscal, e não o desenvolvimento da agricultura ou da pecuária. Neste sentido, Martins (1997) salienta a contradição presente no discurso de ocupar a Amazônia uma das atividades que menos necessita de mão-de-obra (a pecuária) e Becker (1982) destaca que monopólio da terra nas regiões de fronteira tinha uma especificidade que the reduzia o caráter de "fronteira agrícola", uma vez que a produção agropecuária era limitada.

Face à incipiente atividade agropecuária diante do que poderia efetivamente ter sido implementado pelos empresários que se tornaram proprietários e contavam com amplo fomento estatal, Simoni Santos (2015) questiona o próprio termo 
“agrícola" para se referir à fronteira neste momento. De acordo com o autor (2015, p. 123):

(...) mesmo se considerarmos as suas limitações, a observação do desenvolvimento da pecuária como atividade econômica nessas condições somente reforça a relatividade, e talvez mesmo, a inadequação do adjetivo 'agrícola' quando empregado à situação de fronteira. A pecuária acabou também surgindo como atividade primordial no processo de avanço dinâmico da fronteira, fundamentalmente, porque ela, em função de seus baixos coeficientes de capitalização inicial, consolidou-se como o meio para apropriação de vastas extensões de terra, que serviam, simultaneamente, como estratégia de defesa contra a inflação, como fonte de rendimentos associados à valorização fundiária e como meio para a obtenção de incentivos fiscais de toda ordem.

Também relativizando os conteúdos da denominada "fronteira agrícola", Becker (1982) salienta que o que interessava às grandes empresas atraídas para as regiões de fronteira no centro-oeste e norte do Brasil não era a produção para o mercado interno e tampouco a pecuária ou a agricultura. Segundo a autora, os interesses estavam voltados para a "apropriação da terra, ou usufruir dos inventivos e financiamentos, para diversificar investimentos, criar reservas de valor e abrir novos espaços para a penetração do capital” (BECKER, 1982, p. 176).

Neste mesmo sentido, enfatizando a relevância dos investimentos fundiários, Oliveira (1997) destaca que para compreender a colonização em Mato Grosso nas últimas décadas do século $\mathrm{XX}$ é preciso problematizar necessariamente a mercadoria terra, considerando o papel do Estado e das políticas públicas implementadas principalmente a partir da década de 1970. Grande idealizador e patrocinador do espraiamento territorial da acumulação de capital em direção às terras mato-grossenses, o Estado, de modo geral, favoreceu e patrocinou o acesso à terra a grandes capitalistas e grupos econômicos, corroborando acentuadamente com a concentração fundiária por meio de diversos projetos de colonização, agropecuários e políticas territoriais, além de incentivos ou subsídios fiscais, construção de infraestruturas e concessão ou venda a preços irrisórios de terras. Também intervinha por meio da reiteração de uma legislação fundiária permissiva e participando ou sendo conivente aos mais variados mecanismos de burla, corrupção e de grilagem (OLIVEIRA, 1997; MORENO, 2007). 
Como detalha Moreno (2007), o processo de ocupação de terras em Mato Grosso teve a particularidade de privilegiar a monopolização da propriedade privada da terra, apresentando um complexo aparato jurídico e político que teve como uma de suas consequências o favorecimento de interesses dos setores hegemônicos econômicos e políticos. Assim como uma porção significativa do território do CentroOeste e Norte brasileiro, Mato Grosso foi generosamente contemplado com recursos e políticas territoriais principalmente no decorrer da ditadura militar. Programas de incentivos fiscais da SUDAM (Superintendência do Desenvolvimento da Amazônia) atraíam empreendimentos na Amazônia e possibilitavam a transformação de capitalistas nacionais e internacionais em latifundiários.

Sob um discurso de ocupar a Amazônia, realizava-se, como elucida Oliveira (1997) justamente o seu contrário: a consagração do vazio do latifúndio e da terra empregada para fins especulativos, sendo utilizada como reserva de valor e patrimonial. O caráter monopolista do processo de ocupação e colonização do território mato-grossense trouxe violentas consequências ao processo de urbanização primaverense e à dinâmica fundiária e imobiliária a ele atrelada. Tratase de uma concentração fundiária que, se por um lado implicou no gozo rentista de grandes empresários e latifundiários, teve como condição e consequência uma população expropriada de sua própria terra (os indígenas, os posseiros, os camponeses...).

É neste momento em que se começam a ser instituídos os processos que levam a um espaço urbano produzido e reproduzido como mercadoria em Primavera do Leste, bem como alguns dos fundamentos da desigualdade e de suas contradições espaciais. A implantação de cidades em Mato Grosso no decorrer da colonização e ocupação monopolista do território engendrou processos constitutivos da urbanização com características específicas ligadas à concentração fundiária e ao modo pelo qual a fronteira do capital foi sendo configurada, impondo intensa e dramaticamente a lógica da mercadoria e da propriedade privada.

Essa violenta concentração fundiária, acirrada no decorrer dos anos 1970 e 1980 devido aos processos de ocupação e colonização da Amazônia, fica evidente considerando o fato de que em Primavera do Leste, em 1992 e segundo dados do INCRA, 4,2\% das terras estavam em pequenas propriedades, $20,5 \%$ em médias e $75,2 \%$ em grandes propriedades. Eram 888 propriedades rurais cadastradas em 
2013, compondo uma área de $630.458,3$ hectares $^{5}$. Já de acordo reportagem do Jornal Valor Econômico no ano de 2007, apenas seis produtores em Primavera do Leste detinham metade dos 320 mil hectares de lavouras daquele ano ${ }^{6}$.

\section{Da paisagem aos negócios fundiários}

A dominação e a concentração fundiárias de Primavera do Leste ocorreram à medida que fazendas eram loteadas para a criação e expansão do área construída da cidade. Assim, os mesmos "donos" dos latifúndios (com finalidade improdutiva ou destinados às atividades agrárias) são também "donos" dos terrenos no núcleo urbano ou próximo dele. Neste sentido, a constituição da "terra cativa" ${ }^{7}$ no decorrer da ocupação da região de Primavera trouxe em seu bojo a produção não somente que terrenos isolados entre si que têm dono, mas de toda uma cidade. Preenchida dos arcaísmos da questão agrária brasileira - dentre eles, a concentração de terras e a preponderância de terras improdutivas de finalidade rentista - essa cidade que tem dono tem como consequência uma lógica fundiária excludente: nem todos podem ter acesso à propriedade, o que, na sociedade capitalista, tende a determinar o próprio acesso à cidade. Da mesma forma, a propriedade e a cidade passam a ser, como tendência, privilégio somente das classes de renda de maior poder aquisitivo.

Ainda hoje, a colonizadora responsável pelo loteamento do que originaria formalmente a cidade, antiga Colonizadora Cosentino e atualmente Imobiliária e Incorporadora, detém parcela significativa dos imóveis ou terrenos para aluguel ou venda, controlando a incorporação de loteamentos juntamente com outras poucas construtoras e incorporadoras cujos "donos" ainda são essencialmente das famílias "pioneiras" no processo de ocupação e produção da fronteira.

\footnotetext{
${ }^{5}$ Disponíveis em <http://www.incra.gov.br/sites/default/files/uploads/estrutura-fundiaria/regularizacaofundiaria/indices-cadastrais/indices_basicos_2013_por_municipio.pdf>. Acesso em 28 de jun. 2016.

6 "Cresce ainda mais a concentração na produção agropecuária no MT". Zanatta, Mauro. Jornal Valor Econômico. 28 ago. 2007. Disponível em <http://www.valor.com.br/arquivo/1000222620/cresce-aindamais-a-concentracao-na-producao-agropecuaria-no-mt>. Acesso em out. 2017.

7 O marco do início da "terra cativa" ocorreu com a Lei de Terras, de 1850. Por meio desta Lei, o Estado sacramentava a relação entre terra e capital. Asseguravam-se interesses de fazendeiros e comerciantes na iminência de transformações nas condições do regime escravista, determinando a obtenção de terras por compra e venda e legalizando a posse dos títulos das sesmarias de qualquer dimensão não confirmados. A propriedade privada estava garantida e se garantia mão de obra assalariada à terra agora cativa. A elite, que acumulava riqueza com o monopólio sobre escravo, passou a acumular com o monopólio sobre a terra (MARTINS, 1994; 2010).
} 
É considerando a dominação de extensas propriedades empreendida por poucos e poderosos grupos privados que aprofundaremos alguns dos aspectos relacionados a essa uma "urbanização oligopolista". Esse termo foi empregado por Volochko (2015) a respeito das cidades vinculadas mais intensamente à agricultura capitalista mecanizada e se refere a uma urbanização controlada por um pequeno grupo de detentores do poder econômico e político. Nesta urbanização oligopolista, há um maior controle sobre a propriedade privada, ainda hoje predominantemente realizado pelas famílias e grupos que chegaram no início da produção e deslocamento da fronteira, gerando um maior domínio na abertura de loteamentos, no tamanho e no preço dos lotes e imóveis. No mapa $2^{8}$, pode-se claramente notar que mesmas famílias dominavam grande parte das terras ocupadas ou com loteamentos abertos no núcleo urbano já consolidado.

\footnotetext{
${ }^{8}$ Este mapa é uma aproximação da realidade e apresenta generalizações, uma vez que muitos dos lotes já foram vendidos para terceiros e que uma representação precisa apenas poderia ser feita com - levantamento de cada registro de matrícula de cada imóvel da cidade. Como procedimentos metodológicos para a elaboração deste mapa, destacamos: autorização para implantação de loteamentos publicadas em portal da Prefeitura Municipal de Primavera do Leste; entrevistas com corretores imobiliários; consultas sobre empresas e seus respectivos sócios em sites como <https://www.infoplex.com.br>; <http://www.consultasocio.com>.
} 


\section{Mapa 2. Concentração fundiária e urbanização oligopolista em Primavera} do Leste

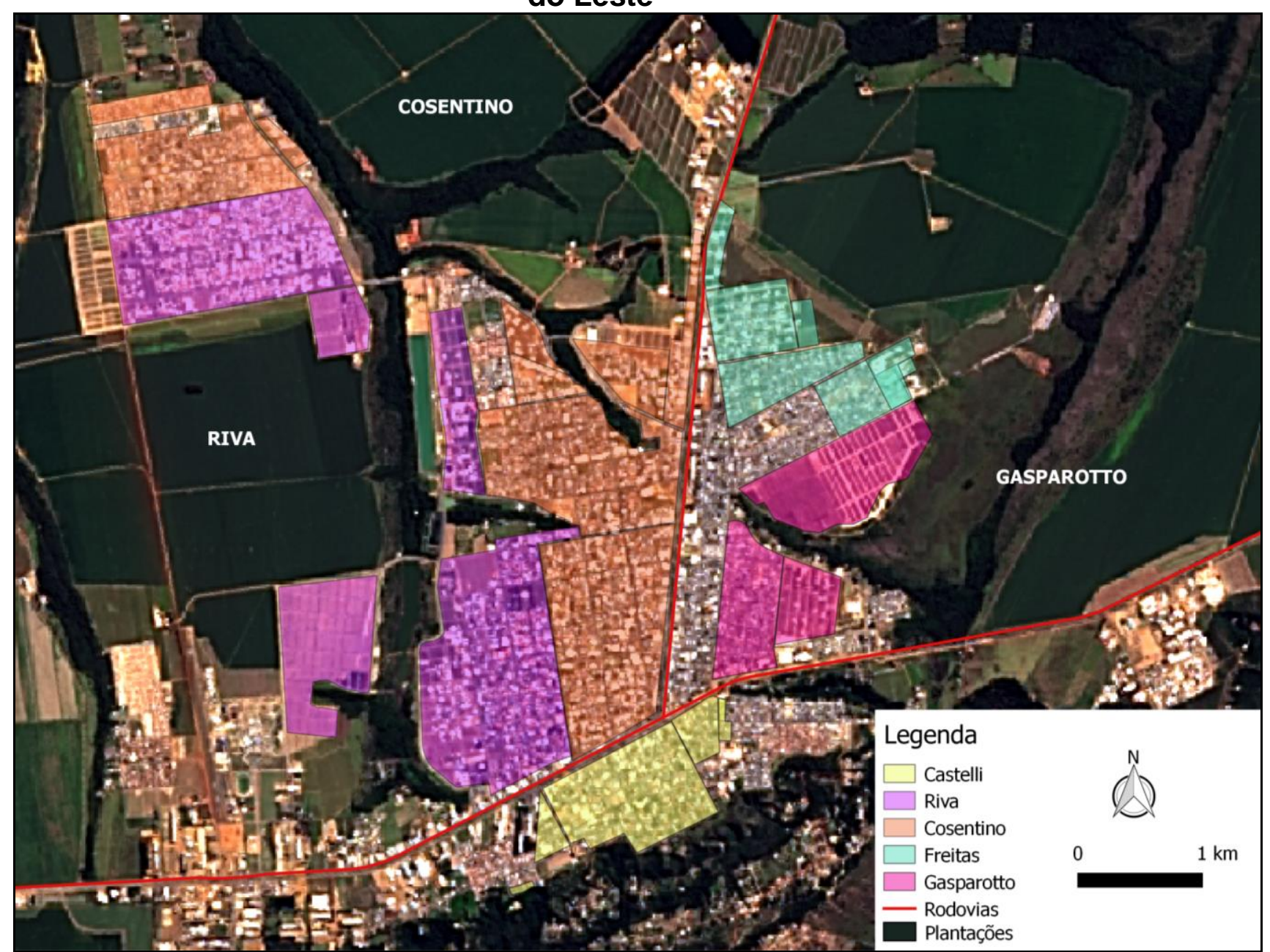

Notam-se extensas parcelas do espaço inicial ou atualmente dominadas por uma única família ou grupo. Algumas delas têm fazendas nas proximidades do núcleo urbano, as quais tendem a ser loteadas com tempo. Mapa elaborado em junho de 2016 por Alcântara, W. M.; Fioravanti, L.M.

As contradições do espaço de Primavera do Leste produzidas no movimento de ocupação do território mato-grossense comandando por poucos "pioneiros" e alicerçada no trinômio terra-poder-capital se revelam nos processos de dominação e apropriação do espaço (e da contradição) específicos nessas cidades. As estratégias desses agentes determinados, os "pioneiros", explicam um modo muito particular de dominação e apropriação do espaço nestas cidades e que se manifestam em uma dinâmica imobiliária com intensa concentração fundiária e extremamente excludente.

A implantação de Primavera foi resultado justamente desses incentivos fiscais do governo federal para a ocupação da Amazônia Legal. Em 1971, um economista 
paulista, considerado pelos primaverenses como um dos principais "pioneiros"9 da cidade, formou a empresa "Primavera do Oeste" em associação com empresários do setor automobilístico. Analisando-se a trajetória dessa empresa, notamos que originalmente foi implantada com o objetivo de realizar atividades agropecuárias. Contudo, embora o grupo de empresários tenha chegado à região subsidiado pela SUDAM e com objetivo formal de implantar um projeto agropecuário, logo a comercialização de terras mostrou-se como um promissor negócio (por meio de um domínio da propriedade e do espaço ainda hoje no comando de poucos). Segundo Oliveira (1997), o aumento do preço médio do hectare nos primeiros anos da ocupação de Primavera do Leste, entre a década de 1970 e 1985, chegou a dois mil por cento. Tal crescimento nos dá a dimensão de que a "invenção" e "produção" de cidades eram extremamente rentáveis aos denominados "pioneiros" da fronteira.

Neste contexto, o projeto agropecuário financiado pela SUDAM cedeu lugar à negociação de terras e à "invenção" de Primavera do Leste, em um processo que se reproduziu, embora com particularidades, em parcela considerável do território matogrossense. Uma parcela dessas terras desse empreendimento agropecuário foi adquirida por Edgard Cosentino, responsável pela implantação do projeto "Cidade Primavera" em 1972 e que totalizava 205 hectares dos 1.100 da fazenda Nova Esperança (adquirida por ele neste mesmo ano). Após a venda da parte de que era sócio na Primavera d'Oeste, Cosentino formou uma Colonizadora (Colonizadora Cosentino) e deu continuidade à sua ideia de implantar uma cidade (CMPL, 2016).

A cidade teve sua origem, dessa forma, a partir do desmembramento de uma única fazenda, de um único dono e dos recursos de uma única Colonizadora, encarregada até a emancipação política da cidade em 1986 por uma série de investimentos e implantação de obras de infraestrutura. Como afirma Arruda (2007), é apenas com a consolidação da ocupação e emancipação do município que as obras de infraestrutura deixam de ser realizadas pelas colonizadoras (sempre favorecidas com generosos incentivos fiscais) e passam a ser empreendidas pelo Estado. Contudo, embora a gestão urbana passe a ser realizada pelo poder público municipal, as colonizadoras, agora sob a forma de imobiliárias ou de incorporadoras,

\footnotetext{
${ }^{9}$ A própria ideia de pioneirismo é carregada de um viés ideológico que coloca as pessoas que chegaram naquele momento como as primeiras a se instalarem no local. Considera a região como um "vazio demográfico" e ignora, dentre outras, as populações indígenas. Além disso, são considerados "pioneiros" somente aqueles que chegaram no processo de expansão da fronteira do capital e que, em um discurso meritocrático, souberam investir, tendo enriquecido e obtido um retorno considerado como merecido graças ao esforço pelo próprio trabalho.
} 
continuam com influência na produção do espaço dessas cidades gestadas na expansão do fronteira do capital. O objetivo era, segundo Arruda (2007, p. 129), "garantir os interesses mercantis, presentes desde o processo inicial de implantação do estabelecimento até os dias atuais, na comercialização dos lotes urbanos e rurais".

Como se nota por meio dos "pioneiros" que chegavam à região de Primavera do Leste - grandes empresários expandido fortemente subsidiados pelo Estado, a fronteira do capital - reforçava-se o imbricamento entre terra, poder e capital, em um processo bastante elucidado por Martins (1994, 2010). As dinâmicas da propriedade privada da terra são fortemente determinadas pelas articulações entre o poder econômico e o político. Assim, como ocorreu tendencialmente no território matogrossense e brasileiro como um todo, a dominação privada de terras bem como a ocupação do que seria a cidade de Primavera do Leste manteve e fortaleceu os privilégios econômicos e políticos de oligarquias, permitindo, sempre com colaboração e forte patrocínio do Estado, que grandes empresários fossem também proprietários e participassem do jogo político.

Há, neste sentido, uma pesada ingerência na expansão dos loteamentos e no próprio planejamento urbano realizada por poucas famílias desde o início da ocupação da cidade. Esses "pioneiros" empregam diversas táticas para controlar a valorização do solo urbano, como a doação de terrenos e abertura gradual de novos loteamentos. Também determinam as formas de aquisição dos lotes (se a à vista, com ou sem financiamento, bem como a quantidade de parcelas) e seu tamanho (variando, em média, de duzentos a seiscentos metros quadrados), instituindo loteamentos inteiros tendencialmente com o mesmo padrão de renda.

A consequência desse processo é a perpetuação de uma dinâmica imobiliária que dificulta ainda mais o acesso dos mais pobres à propriedade. Assim, da mesma forma que na cidade há lotes no loteamento Jardim Riva, um dos mais caros da cidades e implantado pelo "pioneiro" Waldomiro Riva, que ultrapassam meio milhão de reais, também há a população pobre que enfrenta uma série de dificuldades para ter uma casa, seja nas periferias (cujas terras também são em grande medida controladas pelos "pioneiros"), seja em uma favela às margens da rodovia BR-070 que atravessa o núcleo urbano.

Em Primavera do Leste e nas demais cidades cuja produção do espaço urbano é perpassada por uma reprodução do capital realizada por meio de uma 
urbanização extremamente centralizada, há um relativo domínio do modo pelo qual o espaço urbano é homogeneizado (tornado mercadoria, com a transformação de lotes rurais em urbanos), fragmentado (com o parcelamento e venda de lotes e terrenos) e hierarquizado (por meio da abertura de loteamentos mais ou menos valorizados) ${ }^{10}$.

Além da compra e da venda de fragmentos do espaço urbano, tornados homogêneos transformados em mercadoria, há uma hegemonia nos processos de produção do espaço urbano vinculados aos grandes e rentáveis negócios do urbano. Diferentemente de metrópoles em que há uma relativa diversificação dos agentes responsáveis pela incorporação imobiliária, em uma cidade como Primavera do Leste estão usualmente reunidos, em uma só pessoa, família ou grupo empresarial: o proprietário fundiário, o loteador, o corretor imobiliário e, considerando a articulação das oligarquias econômicas e políticas - em certa medida, até o próprio Estado. Nesse contexto, o poder de decisão de poucos sobre os ritmos da dinâmica imobiliária - desde a incorporação de lotes ao perímetro urbano, passando pela obtenção de renda e valorização do espaço - realiza-se, portanto, em processos de maiores magnitude, recrudescendo o processo de segregação espacial.

\section{A imposição de uma homogeneidade social e estética}

Esse domínio dos "donos" sobre a cidade vai além do domínio fundiário. Está na própria determinação e escolha do traçado da cidade, com o estabelecimento de um espaço abstrato e funcional, contribuindo para a programação no tempo e no espaço das atividades da vida urbana. Também envolve aspectos ligados ao próprio cotidiano e que foram sendo delineados ao longo do processo de ocupação de Primavera pelos "donos" e pelas demais famílias "pioneiras". Esse controle está, neste sentido, no que é valorado em relação à cultura e à perspectiva de vida e de trabalho (atrelados à ideia de que, nestas cidades e para todos, é possível enriquecer o tempo todo e somente pelo esforço e pelo trabalho).

Debater os conteúdos dessa cidade que tem dono potencializa o debate do papel da propriedade privada além do plano político e econômico, alcançando o plano social. A ingerência dos chamados "pioneiros" nessas cidades cujo processo

\footnotetext{
10 Retomamos aqui a tríade hierarquização-homogeneização-fragmentação exposta por Lefebvre (2000), a qual tem um papel fundamental na compreensão dos processos constitutivos da produção do espaço e, particularmente, da diferenciação e segregação espaciais.
} 
de urbanização foi relativamente recente e intenso em Mato Grosso nas últimas décadas do século $X X$ tem, dessa forma, tanto desdobramentos estruturais e atuais na dinâmica fundiária quanto viscerais consequências na vida cotidiana.

Por um lado, há um maior controle sobre o preço e os tamanhos dos lotes, em um processo no qual a maior parte dos loteamentos da cidade é gerida por poucos proprietários e que resulta em uma dificuldade ainda maior das pessoas de menor renda para o acesso à moradia e à propriedade. Por outro lado, não somente poucos "donos" ditam a compra e venda de fragmentos do espaço urbano, em um contexto no qual essas próprias cidades surgem como um grande negócio, como há uma espécie de monitoramento daqueles considerados como dotados de legitimidade para pertencer ou não à cidade. Nordestinos, negros e indígenas são com frequência vistos como o "outro" da constituição da fronteira e produção desses espaços, compondo um grupo que não pode tendencialmente morar em determinados loteamentos ou frequentar certos espaços públicos.

Além disso, da mesma forma que outras cidades mato-grossenses como Sorriso e Lucas do Rio Verde, também há uma parcela da população que compõe uma pobreza profundamente estigmatizada e que mora em conjuntos residenciais no geral bastante afastados do centro, como nas casas em Primavera do Leste subsidiadas pelo governo federal por meio do Programa Minha Casa Minha Vida, nos loteamentos Primavera III e Tuiuiú (distantes dos serviços e infraestruturas urbanos, além de contarem com um transporte público precário).

Salvaguardando interesses de classe, os mecanismos disciplinares e repressivos eram e são também exercidos nessas cidades mato-grossenses por meio não somente de empresários, da burocracia do Estado e do aparato policial, mas também pela mídia e pelas instituições religiosas e educacionais, bem como pela difusão de várias mensagens do governo, dos "pioneiros" e da igreja que reiteram a importância de um cotidiano permeado pela experiência e redenção pelo trabalho (GUIMARÃES NETO, 2002; ABREU, 2015).

O discurso do empreendedorismo e do "pioneirismo", que enaltece os vistos como "pioneiros" responsáveis (graças a generosos incentivos fiscais do governo federal e em um lucrativo e rentável negócio) pela implantação da cidade, condena os mais pobres, julgados, segundo parcela dos moradores de Primavera e demais cidades, como preguiçosos e violentos. Devem, nessa linha de raciocínio e segundo discurso local dos moradores e da mídia, não somente morar nas periferias 
afastadas do centro e desprovidas de grande parte da infraestrutura mas também serem, em última instância, expulsos da própria cidade. Aos ricos e aos brancos, é dada à legitimidade e o direito de permanecer e de vivenciar a cidade.

Essas estratégias de domínio do espaço se efetivaram, portanto, em diversas escalas: o controle do espaço amazônico como um todo articulado a interesses econômicos e geopolíticos nacionais, empreendido por meio de projetos e planos de colonização, exigia e somente se realizava por meio de uma pesada fiscalização e vigilância no plano do lugar, na vida cotidiana, em quem chegava à cidade e quem a controlava. Segundo Guimarães Neto (2002), esse domínio do espaço nas cidades que surgiam era crucial para manter nas mãos dos agentes hegemônicos a propriedade da terra (e não dos muitos migrantes que chegavam).

Enfatizando diversas práticas de vigilância sobre a população mais pobre de Primavera do Leste, Cerutti (2004) ressalta a existência de uma "triagem", nas palavras do próprio prefeito da cidade, realizada na década de 1990 para decidir, dentre aqueles de menor renda, quem poderia morar em cada bairro. Em lugares mais distantes do centro da cidade, loteamentos inteiros foram cedidos ou vendidos a preços mais baixos para abrigar a população de menor renda.

Esse controle da população é ainda mais claro quando se trata dos moradores de rua. Com frequência desempenhando atividades temporárias e precárias nas fazendas da região ligadas ao "agronegócio", representam corpos cuja permanência na cidade e visibilidade é reiteradamente negada por aqueles dotados da legitimidade para habitá-la. Cerutti (2004) cita uma ampla campanha na mídia local entre os anos de 1999 e 2000 que construía a imagem de que os moradores de rua - pejorativamente denominados de "pés-inchados" - eram naturalmente preguiçosos ou violentos. Houve inúmeros casos nos quais foram concedidas passagens para as cidades de origem dessas pessoas, bem como mecanismos de expulsão forçada, com ônibus ou caminhões que passavam de madrugada para “recolher" essas pessoas pobres e "deixá-las" em cidades vizinhas. Essas práticas, vale ressaltar, não são uma particularidade de Primavera do Leste. Segundo Arruzzo (2005, p. 110), em outros municípios, "produtores rurais nos informaram de ações da prefeitura em remover os migrantes, buscando 'desenvolvê-los', colocando-os em ônibus que realizavam o trajeto de volta, sendo portanto absolutamente negada sua permanência". 
Tais táticas de domínio do espaço - efetivadas através do monitoramento, vigilância e repressão em relação à população de menor renda nos espaços da cidade bem como na implantação de loteamentos distantes destinados à população mais pobre e na construção de representações pela mídia local dos trabalhadores mais pobres e de moradores de rua - assegura interesses de classe e reproduz tempos e espaços que negam o outro e a diferença.

Deste modo, em Primavera do Leste e em demais cidades que têm dono o peso da homogeneidade se realiza em uma dimensão mais elevada. Imposta desde o início da reprodução da fronteira a partir de grupos hegemônicos que passariam a deter o controle das trajetórias fundiárias, essa homogeneidade também transborda para um desmesurado controle de outros processos que tangem à urbanização. Manifesta-se desde a monotonia do traçado urbano e do padrão arquitetônico até nas decisões oriundas das mais diversas instituições, cujos representantes frequentemente fazem parte das oligarquias econômicas e políticas locais, assim como nas práticas de controle em relação a quem pode ou não permanecer na cidade.

Como vimos, são várias as táticas empregadas para manter intacta a imagem de "cidade vitrine" do "agronegócio" - movida pelo "progresso" e riqueza - na qual supostamente a qualidade de vida prospera, em um movimento de ingerência que envolve não somente a propriedade (embora esteja nela alicerçado), mas práticas de controle e negação dos espaços públicos. Há, neste sentido, uma preocupação desde início da ocupação da cidade com as "representações do espaço" (LEFEBVRE, 2000) ${ }^{11}$ a ela atreladas, o que, para muitos habitantes, parece justificar posturas higienistas.

\section{Considerações Finais}

Assim como tantas outras cidades implantadas em Mato Grosso, Primavera do Leste foi um grande investimento formado tendo como fundamento a produção e reprodução da terra enquanto mercadoria. Oriunda da voracidade e da velocidade

\footnotetext{
${ }^{11}$ As "representações do espaço" compõe um dos elementos da tríade exposta por Lefebvre (2000), juntamente com os "espaços de representação" e a "prática socioespacial". Para o autor, as representações do espaço estão diretamente ligadas ao controle e à ordem do Estado, aos agentes hegemônicos da produção do espaço e à imposição da lógica capitalista (suas relações de produção, seus signos e seus códigos). Por meio do planejamento e de seus estratégias de intervenção, concebem o espaço como geométrico e passível de ser moldado e controlado.
} 
dos processos capitalistas e inserida em um momento no qual a "invenção" e "produção" de cidades surgiam como um rentável investimento, Primavera foi pensada de modo a viabilizar uma acumulação capitalista preponderantemente urbana. Nossa perspectiva procurou mostrar as particularidades de uma cidade apregoada de contradições, cuja violência da constituição e monopolização da propriedade fundiária repercute, a cada dia, em um cotidiano violento de expropriação e de preconceito.

Neste sentido, trouxemos neste artigo o desafio teórico-metodológico de pensar essas cidades cravadas em meio a extensas plantações de soja a partir do urbano. Trata-se de um urbano não meramente necessário à realização da expansão agrícola, mas que se tornou sua própria finalidade por meio da implantação de cidades em um contexto no qual as terras em Mato Grosso eram fragmentadas e loteadas, sendo consideradas como urbanas e passando por um forte processo de valorização.

No processo de direcionamento de capitais e investimentos rumo ao CentroOeste, com a monopolização e dominação capitalista das terras mato-grossenses ora usadas para fins especulativos ora fragmentadas e loteadas, muitas das originando cidades - encontra-se o cerne das explicações das contradições espaciais primaverenses na medida em que é neste momento em que começaram a ser formados os fundamentos ainda hoje produzidos e reproduzidos nessas cidades que passaram a ter "dono". Essa dominação privada da terra é crucial tanto para a compreensão da atual dinâmica fundiária e imobiliária quanto das relações sociais concretas que reproduzem em Primavera do Leste. Os chamados "pioneiros" mobilizaram não apenas um poderoso monopólio fundiário para a efetivação de suas estratégias espaciais como também empreenderam práticas e mecanismos de controle sobre os diversos aspectos de uma vida urbana tendencialmente estilhaçada.

Destacando os negócios fundiários e sua relevância e papel nos processos de urbanização, investigamos as consequências do que atualmente se manifesta como uma cidade controlada por poucos interesses de poucos agentes hegemônicos da produção do espaço em um movimento que permite apontar tendências dos conteúdos da urbanização de demais cidades parcialmente dinamizadas pela agricultura capitalista e que também foram produzidas por meio de um processo de urbanização relativamente recente e intenso. 


\section{REFERÊNCIAS}

ABREU, Rafael Assumpção de. A boa sociedade: história e interpretação sobre o processo de colonização no norte de Mato Grosso durante a Ditadura Militar. Rio de Janeiro, 2015. Tese (Doutorado em Ciência Política). Universidade do Estado do Rio de Janeiro, 298p.

ARRUDA, Zuleika Alves de. Onde está o agro deste negócio? Transformações socioespaciais em Mato Grosso decorrentes do agronegócio. Campinas, 2007. Tese (Doutorado em Ciências), Instituto de Geociências, Universidade Estadual de Campinas.

ARRUZZO, Roberta Carvalho. "Modernização agrícola, trabalho e organização especial na BR-163". In: BERNARDES, Júlia Adão; FREIRE FILHO, Osni de Luna (orgs.). Geografias da soja: BR-163. Fronteiras em mutação. Rio de Janeiro: Arquimedes, 2010.

BECKER, Bertha K. Geopolítica da Amazônia: a nova fronteira de recursos. Rio de Janeiro: Zahar, 1982.

Amazônia. 3ª̣ ed. São Paulo: Ática, 1994.

CERUTTI, Leandro Genoíno. Deslocamento social e trabalho temporário: práticas e relatos de trabalhadores em Primavera do Leste - MT. Mestrado em História, Universidade Federal de Mato Grosso, 109f. Cuiabá, 2004.

GUIMARÃES NETO, Regina Beatriz. A Lenda do Ouro Verde: política de colonização no Brasil Contemporâneo. Cuiabá: UNICEN, 2002.

LEFEBVRE, Henri. La production de l'espace. 4ª ed. Paris: Éditions Anthropos, 2000.

MARTINS, José de Souza. O Poder do Atraso: Ensaios de Sociologia da História Lenta. São Paulo: Hucitec, 1994.

. O tempo da fronteira. Retorno à controvérsia sobre o tempo histórico da frente de expansão e da frente pioneira. Tempo Social; Rev. Sociol. USP, S. Paulo, 8(1): 25-70, maio de 1996.

O Cativeiro da Terra. 9 9 $^{\mathrm{a}}$ ed. São Paulo: Contexto, 2010.

Fronteira: A degradação do outro nos confins do humano. São

Paulo: Contexto, 2014.

MARTINS, Sérgio Manuel Merêncio. A cidade "sem infância" no universo pioneiro de Chapadão do Sul (MS). São Paulo, 1993. Dissertação de Mestrado (Geografia Humana), Universidade de São Paulo.

MORENO, Gislaine. Terra e Poder em Mato Grosso: Políticas e Mecanismos de Burla 1892 - 1992. Cuiabá: EdUFMT/Entrelinhas/FAPEMAT, 2007.

OLIVEIRA, Ariovaldo Umbelino. A fronteira amazônica mato-grossense: grilagem, corrupção e violência. 1997. 495f. Tese (Livre-Docência) - Faculdade de Filosofia, Letras e Ciências Humanas, Universidade de São Paulo, São Paulo, 1997. 
Modo capitalista de produção, agricultura e Reforma Agrária. São Paulo: Labur Edições, 2007. A mundialização da agricultura brasileira. lânde Editorial, São

Paulo, 2016.

SIMONI SANTOS, César Ricardo. A fronteira urbana: urbanização, industrialização e mercado imobiliário no Brasil. São Paulo: PPGH - USP/FAPESP/ Annablume, 2015.

VOLOCHKO, Danilo. "Da extensão do campo à centralização do urbano: elementos para o debato da produção do espaço em Mato Grosso". Revista Mato-Grossense de Geografia, Cuiabá, n.16, p. 18-38, 2013.

. "Terra, poder e capital em Nova Mutum - MT: elementos para o debate da produção do espaço nas 'cidades do agronegócio'”. GEOgraphia, Rio de Janeiro, v. 17, n. 35 , p. $40-67,2015$.

\section{NOTAS DE AUTOR}

\section{CONTRIBUIÇÃO DE AUTORIA}

Lívia Maschio Fioravanti - Concepção. Coleta de dados, Análise de dados, Elaboração do manuscrito, revisão e aprovação da versão final do trabalho

\section{FINANCIAMENTO}

Não se aplica.

\section{CONSENTIMENTO DE USO DE IMAGEM}

Não se aplica.

APROVAÇÃO DE COMITÊ DE ÉTICA EM PESQUISA

Não se aplica.

\section{CONFLITO DE INTERESSES}

Não se aplica.

\section{LICENÇA DE USO}

Este artigo está licenciado sob a Licença Creative Commons CC-BY. Com essa licença você pode compartilhar, adaptar, criar para qualquer fim, desde que atribua a autoria da obra.

\section{HISTÓRICO}

Recebido em: 14-01-2019

Aprovado em: 20-02-2019 